J. Lake Sci. (湖泊科学), 2014, 26(4):515-521

http://www. jlakes. org. E-mail : jlakes@niglas.ac.cn

(c) 2014 by Journal of Lake Sciences

\title{
1990s 以来气候变化和人类活动对洪湖流域径流影响的定量辨识"
}

\author{
夏智宏, 刘 敏, 王 苗, 王 凯, 秦鹏程 \\ （武汉区域气候中心,武汉 430074）
}

\begin{abstract}
摘 要: 为针对性地提出洪湖流域水资源适应与应对气候变化和人类活动影响的措施, 保护洪湖流域生态资源, 促进其 可持续发展, 采取分布式水文模型 SWAT 定量辨识了 1990s 流域城镇快速发展以来气候变化和人类活动对洪湖流域地表 径流的影响程度. 结果表明: 近 20 年来, 人类活动是洪湖流域地表径流减少的主要原因, 其影响量占径流减少量的 $63.72 \%$,气候变化的影响占 $36.28 \%$. 但不同阶段人类活动与气候变化对流域径流影响的程度不同, $1990 \mathrm{~s}$ 气候变化对流 域径流的影响量高于人类活动, $2000 \mathrm{~s}$ 气候变化对流域径流的影响量低于人类活动,近 20 年来的水土保持措施已经发挥 了较好的径流调节和保水效益.
\end{abstract}

关键词: SWAT 模型;气候变化;人类活动;洪湖流域;径流

\section{Quantitative identification of the impact of climate change and human activity on runoff in Lake Honghu basin since 1990s}

XIA Zhihong, LIU Min, WANG Miao, WANG Kai \& QIN Pengcheng

(Wuhan Regional Climate Center, Wuhan 430074, P. R. China)

\begin{abstract}
In order to propose the measures of adaptation and response to the impact of climate change and human activity on runoff in Lake Honghu basin, to protect the ecological resources of Lake Honghu basin, and to promote its sustainable development, this paper used SWAT model to quantitatively identify the impact of climate change and human activity on runoff in Lake Honghu basin since 1990s. The results show : in recent 20 years, human activity is the main reason for the reduction of runoff in Lake Honghu wetland, its contribution to the reduction of runoff is $63.72 \%$, with a contribution of $36.28 \%$ from climate change. The level of influence on runoff change in Lake Honghu Basin varies in different stages, with a higher influence of climate change in 1990s but a higher influence of human activity in 2000s. The measures of water and soil conservation have generated the benefits of runoff adjustment and water conservation in recent 20 years.
\end{abstract}

Keywords: SWAT model; climate change; human activity; Lake Honghu basin; runoff

随着全球气候变化和人类活动影响的加剧, 水资源短缺和环境恶化已经成为世界性的问题, 是当前人 类面临的严峻挑战之一 ${ }^{[1]}$. 对洪湖流域而言, 近 50 年来,年平均气温呈极显著的上升趋势; 年降水量呈缓慢 增加趋势,但时空分布不均;春、夏、冬季和年蒸发量均呈上升趋势;极端旱涝事件交替转换周期缩至 4 年左 右 ${ }^{[2]}$. 人类活动同样显著影响着洪湖流域水资源与生态环境,1950s 中期到 $1970 \mathrm{~s}$ 末大规模的水利建设使流 域水系河网发生重大变化, 1980s 未围网养殖致使流域水质逐渐恶化, 进人 1990s 城镇化快速发展使流域不 透水层范围不断扩大. 气候变化和人类活动的双重影响已经导致洪湖流域湖泊面积缩小, 早涝频率明显升 高, 枯水期提前, 时间延长, 水位波幅增大, 水质富营养化, 进而威胁到洪湖流域生态安全. 如 1998 和 2010 年 的洪涝以及 2011 年的冬春季连旱, 使洪湖流域及其生态系统遭受极大危害. 因此客观定量地评价气候变化 和人类活动对洪湖流域水资源的影响有助于未来水资源的合理开发和可持续利用,对于适应气候变化的对 策研究也具有重要意义. 有关气候变化和人类活动对洪湖流域影响的研究, 大多是从流域水资源、水环境、 河湖环境演变、土地覆被、气象灾害对气候变化和人类活动的响应以及生态环境综合评价等方面着手 ${ }^{[3-10]}$,

* 中国气象局气候变化专项项目 (CCSF2012-05) 资助. 2013-07-10 收稿;2013-11-21 收修改稿. 夏智宏 (1981 ), 男,工程师;E-mail:zhihongxia@ 126. com. 
缺乏气候变化和人类活动对洪湖流域水资源影响贡献率定量分析的研究成果. 国内外有关气候变化和人类 活动对流域水资源影响贡献的区分量化研究, 采取的主要技术手段有长序列资料对比分析法、试验对比分 析法及流域水文模拟等 ${ }^{[11]}$. 由于水文模拟法具有能弥补缺乏长序列实测径流资料和能保证评价期与基准期 自然径流成因一致等特点 ${ }^{[12]}$, 因此基于统计和物理的水文模拟成为目前区分量化气候变化和人类活动对河 川径流影响贡献的主要方法, 并广泛应用于我国的北方地区, 但在长江中下游地区应用较少 ${ }^{[13-20]}$. 本文选择 长江中下游具有代表性的洪湖流域为研究对象, 采用基于 SWAT 模型的径流影响分割分析法, 定量辨识 1990s 洪湖流域城镇化迅速发展以来, 气候变化和人类活动对洪湖流域地表径流的影响程度, 为保护洪湖流 域水资源、促进其生态可持续发展提供科学依据.

\section{1 研究区概况}

洪湖流域位于亚热带中纬度边缘, 流域面积 $11152 \mathrm{~km}^{2}$ (图 1), 为典型的北亚热带湿润季风气候区, 光热 充足, 雨热同季, 无霜期长, 适宜多种农作物生长, 有 “鱼米之乡” 的美称. 常年年均气温 $17.0^{\circ} \mathrm{C}$, 年均降水量 $1278.3 \mathrm{~mm}$, 无霜期 $250 \mathrm{~d}$ 以上, 夏半年 $\left(4-10\right.$ 月) 降水量占全年降水总量的 $77 \%{ }^{[21-22]}$. 降水形成的地表径流与地 下水以及长江与汉水带来的过境客水是洪湖流域水资源的主要构成, 年均地表径流量达到 $36.40 \times 10^{8} \mathrm{~m}^{3}$.

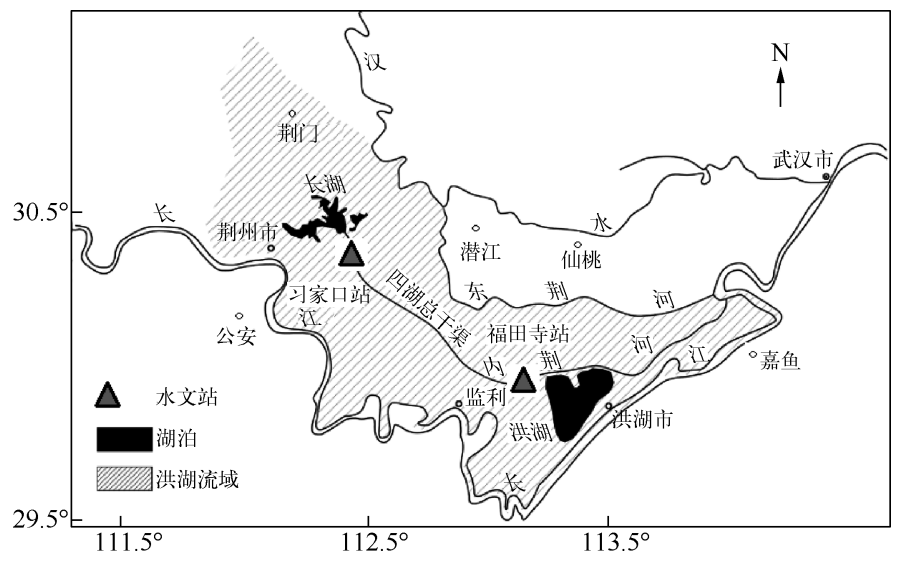

图 1 洪湖流域地理位置

Fig. 1 Location of Lake Honghu basin

洪湖是洪湖流域最大的淡水湖, 也是中国 7 大淡水湖之一, 湖面面积 $348.2 \mathrm{~km}^{2}$, 位于长江中游北岸, 长 湖、三湖、白鹭湖的下游, 通过四湖总干渠承接这 3 个湖泊与区间来水, 是长江和汉水支流东荆河之间的洼 地隼塞湖, 最高水位 $24.58 \sim 27.18 \mathrm{~m}$, 最低水位 $22.87 \sim 23.92 \mathrm{~m}$, 多年平均水位 $24.43 \mathrm{~m}$, 年水位变幅为 $1 \sim$ $4 \mathrm{~m}^{[23]}$. 洪湖具有调蓄、供水、灌溉、湿地生物栖息地、养殖、航运和旅游等多种功能, 在长江中下游浅水湖泊 湿地中具有代表性.

\section{2 资料收集与处理}

\section{1 地理空间数据}

2.1.1 地形数据 洪湖流域地形数据来源于国家测绘与地理信息局 $1: 5$ 万基本比例尺地形图, 用于提取水 系、汇流区域、地形特征参数等信息.

2.1 .2 土地利用/覆被数据 洪湖流域土地利用/覆被数据来源于中国科学院武汉地球物理与测量研究所. 包括比例尺为 $1: 25$ 万的 1980 年和 2005 年土地利用/覆被数据、比例尺为 $1: 5$ 万的 1996 年土地利用/覆被 数据. 本研究中, 分别以 $1980 、 1996 、 2005$ 年的土地利用/覆被数据表征 $1980 \mathrm{~s} 、 1990 \mathrm{~s} 、 2000 \mathrm{~s}$ 的土地利用/覆被 情况.

2.1 .3 土壤数据 洪湖流域土壤数据来源于中国科学院南京土壤研究所 1995 年编制的 $1: 100$ 万中国土壤 
数据库. 考虑到其土壤物理特性与 SWAT 模型采用的美制标准的不同 (如粒径等级), 在充分采纳前人的经 验和知识的前提下 ${ }^{[24-25]}$, 将土壤属性转换至美制标准.

\section{2 气象数据}

洪湖流域气象数据来源于湖北省气象信息保障中心, 包括石首、监利、洪湖等 11 个气象台站 $1961-$ 2011 年逐日平均气温、最高/最低气温、降水、相对湿度、风速等要素, 用于获取 SWAT 天气发生器并驱动 SWAT 模型进行径流模拟.

\section{3 水文数据}

水文数据来源于湖北省水文局, 包括习家口水文站 1964-1974 年、2008-2011 年逐日流量和福田寺水 文站 2008-2010 年逐日流量 (图 1). 考虑到长湖对洪湖流域中下游的调蓄作用, 利用习家口水文站流量数 据计算长湖的调蓄参数, 以反映人为调蓄对洪湖湿地水资源模拟的影响. 福田寺水文站流量数据则用于率 定模型的参数和评价模型在洪湖流域的适用性.

\section{3 研究方法}

根据研究区域资料情况, 本文采用基于 SWAT 模型的水文模拟分割分析法对气候变化与人类活动对洪 湖流域地表径流影响贡献率进行辨识.

\subsection{SWAT 模型径流模拟计算方法}

SWAT 模型的产流模拟不同于一般的统计模型, 它包括气温控制降水形态、冰雪融化、蒸散发、地下径流 补给等物理过程, 并最终导致产流量的变化,因此具有很强的物理机制,适用于模拟不同土地利用及多种土 地管理措施对水文的长期影响, 其水文计算基于如下水量平衡方程:

$$
s w_{t}=s w_{0}+\sum_{i=1}^{t}\left(R_{\text {day }}-Q_{\text {surf }}-E_{\mathrm{a}}-W_{\text {seep }}-Q_{\text {gw }}\right)
$$

式中, $s w_{t}$ 为土壤最终含水量 $(\mathrm{mm}), s w_{0}$ 为土壤前期含水量 $(\mathrm{mm}), t$ 为时间步长 $(\mathrm{d}), R_{\mathrm{day}}$ 为第 $i$ 日降水量 $(\mathrm{mm}), Q_{\text {surf }}$ 为第 $i$ 日的地表径流 $(\mathrm{mm}), E_{\mathrm{a}}$ 为第 $i$ 日的蒸发量 $(\mathrm{mm}), W_{\text {seep }}$ 为第 $i$ 日土壤剖面地层的渗透量和 侧流量 $(\mathrm{mm}), Q_{\mathrm{gw}}$ 为第 $i$ 日的基流量 $(\mathrm{mm})^{[26-27]}$.

SWAT 模型适用性评价采用 Nash 模型效率系数 $E n s^{[28]}$ 和相关系数 $R^{2}$ 来评价 ${ }^{[29]}$ :

$$
\begin{gathered}
\text { Ens }=1-\frac{\sum_{i=1}^{n}\left(Q_{\mathrm{obs}, i}-Q_{\mathrm{sim}, i}\right)^{2}}{\sum_{i=1}^{n}\left(Q_{\mathrm{obs}, i}-\bar{Q}_{\mathrm{obs}}\right)^{2}} \\
R^{2}=\frac{\left(\sum_{i=1}^{n}\left(Q_{\mathrm{obs}, i}-\bar{Q}_{\mathrm{obs}}\right)\left(Q_{\mathrm{sim}, i}-\bar{Q}_{\mathrm{sim}}\right)\right)^{2}}{\sum_{i=1}^{n}\left(Q_{\mathrm{obs}, i}-\bar{Q}_{\mathrm{obs}}\right)^{2} \sum_{i=1}^{n}\left(Q_{\mathrm{sim}, i}-\bar{Q}_{\mathrm{sim}}\right)^{2}}
\end{gathered}
$$

式中, Ens 为 Nash-Sutcliffe 效率系数, $R^{2}$ 为相关系数平方, $Q_{\mathrm{obs}, i}$ 为天然流量, $Q_{\mathrm{sim}, i}$ 为模拟流量, $\bar{Q}_{\mathrm{obs}}$ 为多年平均 实测流量, $\bar{Q}_{\mathrm{sim}}$ 为多年平均模拟流量, $n$ 为模拟流量序列长度.

\section{2 径流影响分割分析方法}

本文将人类活动和气候变化视为影响该洪湖湿地地表径流变化的两个相互独立因子, 其中人类活动以 土地利用/覆被变化表征. 选用 SWAT 模型, 应用实测径流数据率定模型参数, 获取基准期的模拟径流深 $W_{\mathrm{B}}$. 保持基准期土地利用/覆被类型不变, 输人评价期的气候要素驱动 SWAT 模型, 获得仅考虑气候变化影 响的评价期模拟径流深 $W_{\mathrm{HN}}$; 同时输人评价期气候要素和土地利用/覆被资料驱动 SWAT 模型, 获取考虑气 候变化和人类活动共同影响的评价期模拟径流深 $W_{\mathrm{HR}}$, 采用分割分析方法 (如公式 (4) (8)) 分别得到评 价期气候变化和人类活动对洪湖流域径流影响的贡献率 $\eta_{\mathrm{H}}$ 和 $\eta_{\mathrm{C}}$.

$$
\Delta W_{\mathrm{T}}=W_{\mathrm{HR}}-W_{\mathrm{B}}
$$




$$
\begin{gathered}
\Delta W_{\mathrm{H}}=W_{\mathrm{HR}}-W_{\mathrm{HN}} \\
\Delta W_{\mathrm{C}}=W_{\mathrm{HN}}-W_{\mathrm{B}} \\
\eta_{\mathrm{H}}=\Delta W_{\mathrm{H}} / \Delta W_{\mathrm{T}} \times 100 \% \\
\eta_{\mathrm{C}}=\Delta W_{\mathrm{C}} / \Delta W_{\mathrm{T}} \times 100 \%
\end{gathered}
$$

式中, $\Delta W_{\mathrm{T}}$ 为评价期的人类活动和气候变化共同作用对径流深的影响量, $\Delta W_{\mathrm{H}}$ 为评价期的人类活动对径流深 的影响量, $\Delta W_{\mathrm{C}}$ 为评价期的气候变化对径流深的影响量.

\section{4 结果与分析}

\section{1 水文模型适用性评价}

应用 AVSWAT2005 自带的基于 LH-OAT 方法的敏感性分析工具 ${ }^{[30]}$, 选取 27 个模型输人参数进行参数 敏感性分析试验, 设置参数值采样间隔为 10 , 进行了 280 次比较判断, 确定了敏感性等级最高的 5 个参数, 分别为 $\mathrm{CN}_{2} 、$ SOL_AWC、ESCO、GW_REVAP 和 GW_DELAY.

利用 2000s 土地利用/覆被资料, 选用 2008-2009 年福田寺水文站径流实测数据, 根据“先调整水量平 衡, 再调整过程; 先调整地表径流, 再调整土壤水、蒸散发和地下径流” 的原则对模型参数进行逐月水量平衡 校正, 模型率定后的模拟值和实测值拟合很好 (图 2), 率定结果显示 $R^{2}=0.94, E n s=0.86$. 选用 2010 年福田 寺水文站径流实测数据对模型进行验证, 逐月模拟结果显示 $R^{2}=0.94, E n s=0.88$, 表明 SWAT 模型适用于 洪湖湿地水资源模拟. 参数率定结果如表 1 所示.

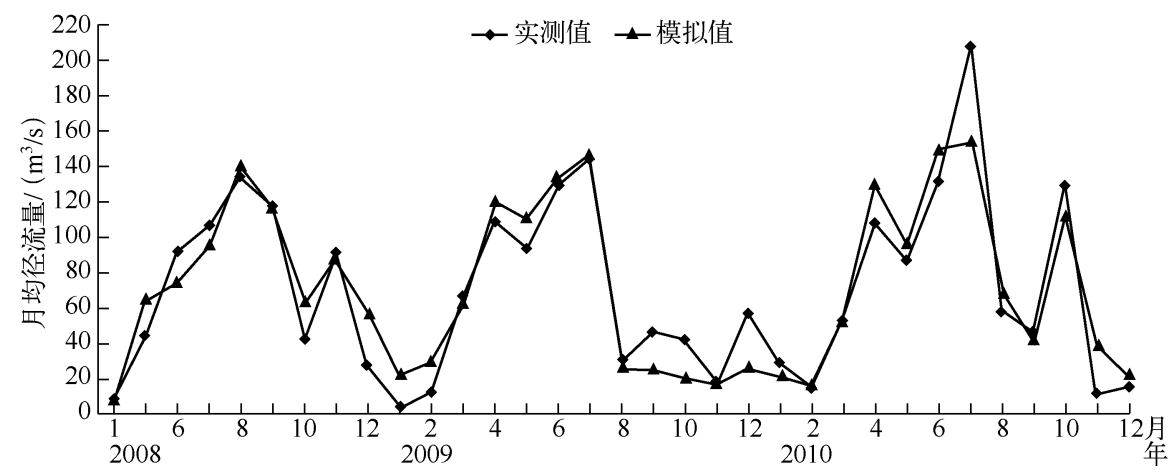

图 2 模型率定期与验证期实测与模拟径流量对比

Fig. 2 Comparing runoff of calibration period with verification period

表 1 SWAT 模型率定的主要参数

Tab. 1 Main calibration parameters in SWAT model

\begin{tabular}{cccccc}
\hline 敏感性等级 & 输人文件 & 校准参数 & 参数含义 & 值域/变化范围 & 参数值 \\
\hline 1 & $* . \mathrm{mgt}$ & $\mathrm{CN}_{2}$ & 半湿润径流曲线系数 & $\pm 25 \%$ & 78 \\
2 & $* . \mathrm{sol}$ & $\mathrm{SOL} \_\mathrm{AWC} /(\mathrm{mm} / \mathrm{mm})$ & 土壤前期含水量 & $0 \sim 1$ & 0.20 \\
3 & $* . \mathrm{hru}$ & $\mathrm{ESCO}$ & 土壤蒸发补偿系数 & $0 \sim 1$ & 0 \\
4 & $* . \mathrm{gw}$ & $\mathrm{GW}$ GREVAP & 地下水蒸发系数 & $0.02 \sim 0.20$ & 0.02 \\
5 & $* . \mathrm{gw}$ & $\mathrm{GW}$ _DELAY/d & 地下径流延迟时间 & $0 \sim 500$ & 31 \\
\hline
\end{tabular}

\section{2 气候变化和人类活动对径流影响辨识}

考虑到 1990s 以来洪湖流域城镇化进程加快, 人类活动以城镇化带来的土地覆被类型变化为主要表现 形式, 因此本文用洪湖流域土地利用/覆被变化表征人类活动的影响. 以 1980s 作为基准期, 采用基于 SWAT 模型的分割分析法分阶段辨识 1990-2011 年气候变化和人类活动对洪湖流域径流深影响的贡献率. 结果表 明, 受环境变化的影响, 相对基准期而言, 1990s 径流深呈增加趋势, 2000s 呈减少趋势, 减少量是 1990s 增加 
量的 1.7 倍. 不同时期人类活动和气候变化对径流深影响的贡献率不同, $1990 \mathrm{~s}$ 气候变化对径流深的影响贡 献率高于人类活动, 受其影响的径流深增加量占总增加量的 $52.35 \% ; 2000 \mathrm{~s}$ 人类活动影响的贡献率高于气 候变化, 受其影响的径流深减少量占总减少量的 55.62\%.2000 年以后气候因素和人类活动在对径流深的绝 对影响量均高于 1990s. 总体上看, 1990-2011 年, 人类活动是地表径流减少的主要原因,其影响的贡献率占 径流减少量的 $63.72 \%$, 气候变化影响的贡献率占 $36.28 \%$ (表 2 ).

表 $21990 \mathrm{~s}$ 和 $2000 \mathrm{~s}$ 人类活动与气候变化对洪湖流域地表径流变化的影响 *

Tab. 2 The impact of climate change and human activity on runoff in 1990s and 2000s in Lake Honghu basin

\begin{tabular}{|c|c|c|c|c|c|c|c|}
\hline \multirow{2}{*}{ 时段 } & \multicolumn{3}{|c|}{ 年均地表径流深/mm } & \multicolumn{2}{|c|}{ 人类活动影响 } & \multicolumn{2}{|c|}{ 气候因素影响 } \\
\hline & 基准期土地利用 & 实际土地利用 & 总变化量 & 变化量/mm & 贡献率/\% & 变化量/mm & 贡献率/\% \\
\hline 基准值 & 352.76 & - & - & - & - & - & - \\
\hline $1990-1999$ 年 & 366.37 & 378.77 & 26.01 & 12.40 & 47.65 & 13.61 & 52.35 \\
\hline $2000-2009$ 年 & 333.68 & 309.77 & -42.99 & -23.91 & 55.62 & -19.08 & 44.38 \\
\hline 1990-2011 年 & 348.54 & 341.13 & -11.63 & -7.41 & 63.72 & -4.22 & 36.28 \\
\hline
\end{tabular}

* 不考虑人类活动影响时, 采用的基准期土地利用数据为 $1980 \mathrm{~s}$ 土地利用数据; 考虑人类活动影响时采用对应的实际土 地利用数据, 其中 1990-1999 年径流模拟采用 1990s 土地利用数据, 2000 年以后的径流模拟采用 $2000 \mathrm{~s}$ 土地利用数据.

\section{3 土地利用/覆盖变化对径流影响分析}

分别提取洪湖流域 1980s、1990s 和 2000s 土地利用/覆被数据( 图 3), 研究土地利用类型变化与径流变 化的关系. 结果表明 (表 3 ), 1990s 相对 1980s, 农村居民地、林地、水体、城镇建设用地面积分别增长

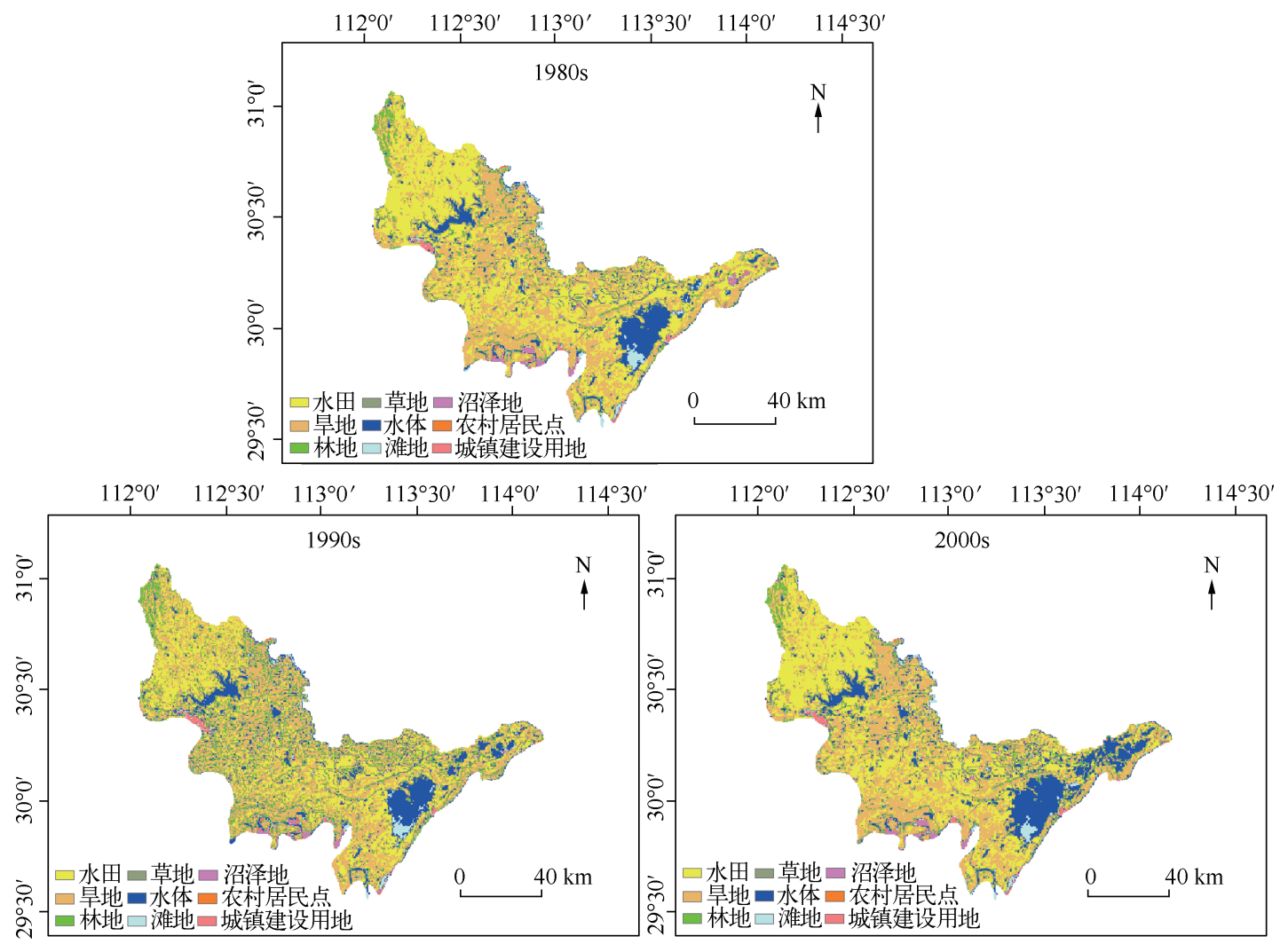

图 3 1980s、1990s 和 2000s 洪湖流域土地利用空间分布

Fig. 3 Spatial distribution of landuse in 1980s, 1990s and 2000s in Lake Honghu basin 
$146.53 \%$ 、 $16.44 \% 、 17.42 \%$ 和 $6.33 \%$, 滩地、沼泽地、耕地、草地分别减少了 $25.79 \% 、 25.29 \%$ 、 $8.86 \%$ 和 $8.15 \%$, 径流量增加了 $3.86 \%$. 分析其原因,一方面是由于降水量的增加, 另一方面, 由于人口增长加速、经 济扩张式发展和城市化进程加快, 大量耕地和部分林地、草地、水体、沼泽地转变为城镇建设用地和农村居 民用地, 导致洪湖流域不透水层面积增加, 抵消了由林地和水体面积增加引起的径流减少的幅度. 2000s 相 对 $1990 \mathrm{~s}$, 草地、水体、滩地、城镇建设用地和沼泽地面积分别增加了 $40.27 \% 、 22.21 \% 、 11.06 \% 、 7.65 \%$ 和 $6.28 \%$, 农村居民点、林地和耕地面积分别减少了 $58.25 \%$ 、 $13.13 \%$ 和 $0.98 \%$, 径流量减少 $8.92 \%$. 分析其 原因, 一方面是由于降水量减少, 另一方面是由于草地、水体、沼泽地覆盖率的增加使土壤咜水能力增强、拦 截作用加大, 尽管城镇建设用地面积继续扩张, 但是流域前期的水土保持措施的蓄水功能效益得到发挥, 抵 消了城镇化引起的径流增加.

总体上看,近 20 年来洪湖流域水土保持工作得到加强, 洪湖流域的水体、草地面积大幅增加, 林地的面 积得到有效恢复与保护, 尽管城市建设用地持续增加, 但径流量仍然下降了 $5.41 \%$, 可见水土保持措施发挥 了较好的径流调节和保水效益.

表 3 洪湖流域不同年代土地利用与径流变化 (\%)

Tab. 3 The rate of runoff and landuse change in different decades in Lake Honghu basin

\begin{tabular}{|c|c|c|c|c|c|c|c|c|c|}
\hline 时段 & 水田 & 旱地 & 林地 & 草地 & 水体 & 滩地 & 城镇建设用地 & 农村居民点 & 沼泽地 径流深 \\
\hline $1990 \mathrm{~s}$ 相对于 $1980 \mathrm{~s}$ & -7.88 & -0.98 & 16.44 & -8.15 & 17.42 & -25.79 & 6.33 & 146.53 & $-25.29 \quad 3.86$ \\
\hline $2000 \mathrm{~s}$ 相对于 $1990 \mathrm{~s}$ & 0.84 & -1.82 & -13.13 & 40.27 & 22.21 & 11.06 & 7.65 & -58.25 & $6.28-8.92$ \\
\hline $1990-2011$ 年相对于 $1980 \mathrm{~s}$ & -7.11 & -2.78 & 1.15 & 28.84 & 43.50 & -17.58 & 14.47 & 2.93 & $-20.60-5.41$ \\
\hline
\end{tabular}

\section{5 结论与讨论}

1) SWAT 模型在洪湖流域径流模拟验证期的效率系数和相关系数平方分别达到 0.88 和 0.94 , 表明该 模型适用于洪湖流域径流模拟,可用于辨识气候变化和人类活动对洪湖流域径流的影响.

2) 受气候变化和人类活动共同影响,相对于基准期, 1990-2011 年洪湖流域年均地表径流深减少了 $11.63 \mathrm{~mm}$. 其中 $1990 \mathrm{~s}$ 径流深呈增加趋势; 而 $2000 \mathrm{~s}$ 呈减少趋势, 减少量是 $1990 \mathrm{~s}$ 增加量的 1.7 倍.

3) 近 20 年来, 人类活动是洪湖流域地表径流减少的主要原因,其影响的贡献率占径流减少量的 $63.72 \%$,气候变化影响贡献率占 $36.28 \%$. 但不同阶段人类活动与气候变化对洪湖流域地表径流影响的程 度不同, 1990s 气候变化对洪湖流域地表径流影响的贡献率高于人类活动, 2000s 则相反.

4 ) 相对于基准期,近 20 年来洪湖湿地的水体、草地面积大幅增加,林地的面积得到有效恢复与保护. 尽 管城市建设用地持续增加, 但年均径流量仍然下降了 $5.41 \%$, 表明水土保持措施发挥了较好的径流调节和 保水效益.

5 ) 广义的人类活动包括人口增长、城市化水平发展、植被增减变化、硬覆盖变化、水利设施对截留的影 响、流域内水体小循环等, 本文为研究城镇化快速发展阶段的人类活动对洪湖流域水资源的影响, 以土地覆 被类型的变化来表征人类活动,在后续研究中将进一步区分不同人类活动对径流变化的影响.

\section{6 参考文献}

[ 1 ] 李子君,李秀涁. 近 45 年来降水变化和人类活动对潮河流域年径流量的影响. 地理科学, 2008,28(6):809-813.

[2] 武汉区域气候中心. 中国气象局气候变化专项 (CCSF2012-05) “气候变化对长江中游典型湖泊湿地的影 响”,2012.

[ 3 ] 蔡述明,王学雷. 江汉平原四湖地区生态环境综合评价. 长江流域资源与环境, 1993,2(4):356-364.

[4] 李昌峰, 张鸿辉. 建国以来人类活动对湖北省四湖地区水环境的影响研究. 国土与自然资源研究, 2003, (4): $68-70$.

[5] 李昌峰, 高俊峰, 张鸿辉. 近 50 年来人类活动对四湖地区河湖环境演变的影响. 地域研究与开发, 2004,23(5): $120-124$. 
[6] 何 浩,刘章勇. 自然与人为干扰对四湖地区涝渍生态系统的影响. 长江大学学报: 自科版,2006,3(3):179-182.

[ 7 ] 桂 峰,于 革, 赖格英. 洪湖流域自然农耕条件下营养盐沉积输移演化模拟研究. 沉积学报, 2006,24 (3): 334-338.

[8] 桂 峰,于 革. 20 世纪 80 年代以来洪湖流域营养物质输移模拟研究. 长江流域资源与环境, 2007,16(22): 179-182.

［9］吴启侠,朱建强,耿显波. 江汉平原四湖流域降水特征分析. 中国农业气象,2008,29(2):146-150.

[10］金卫斌,熊勤学,薛 莲. 基于 MODIS-EVI 时序数据的江汉平原四湖地区土地覆盖动态分析. 湖北农业科学,2011, 50 (11) : 2220-2224.

[11] 张建云,王国庆.气候变化对水文水资源影响研究. 北京:科学出版社,2007.

[12] 张爱静, 王本德, 曹明亮. 气候变化和人类活动对径流影响贡献的研究概况. 东北水利水电, 2012, (1):6-9.

[13] 刘吉峰,霍世青,李世杰等. SWAT 模型在青海湖布哈河流域径流变化成因分析中的应用. 河海大学学报: 自然科学 版, $2007, \mathbf{3 5}(2): 159-163$.

[14] 胡宏昌, 王根绪, 李 志等. 渭河径流对 LUCC 和气候波动的响应研究. 人民黄河,2008,30(7):25-26.

[15］王国庆,张建云, 刘九夫等.气候变化和人类活动对河川径流影响的定量分析. 中国水利,2008,(2):55-58.

[16］黄玉霞,王宝鉴,张 强等.气候变化和人类活动对石羊河流域水资影响评价. 高原气象,2008,27(4):867-872.

[17] 叶许春,张 奇,刘 健等.气候变化和人类活动对鄱阳湖流域径流变化的影响研究. 冰川冻土,2009,31 (5): 836-842.

[18］江善虎,任立良,雍 斌等.气候变化和人类活动对老哈河流域径流的影响. 水资源保护,2010,26(6):1-4.

[19］朱颖洁,郭纯青,黄夏坤.气候变化和人类活动影响下西江梧州降水径流演变研究. 水文,2010,30(3):50-55.

[20] 王 俊,陈亚宁,陈忠升. 气候变化与人类活动对博斯腾湖人湖径流影响的定量分析. 新疆农业科学,2012,49(3): 581-587.

[21] 项国荣. 四湖地区湿地农业持续发展研究. 北京:科学出版社,1997:271.

[22］王苏民,窦鸿身. 中国湖泊志. 北京:科学出版社, 1998:580.

[23] 王学雷,宁龙梅, 肖 锐. 洪湖湿地恢复中的生态水位控制与江湖联系研究. 湿地科学,2008,6(2) :316-320.

[24] 龚子同,张甘霖,陈志诚等. 以中国土壤系统分类为基础的土壤参比. 土壤通报,2002,33(1):1-5.

[25] 王庆云,徐能海. 湖北省土系概要.武汉:湖北科技出版社,2001.

[26] 杨宏伟,许崇育. 东江流域典型子流域土地利用/覆被变化对地表径流影响. 湖泊科学,2011,23(6):991-996.

[27］孙 瑞,张雪芹. 基于 SWAT 模型的流域径流模拟研究进展. 水文,2010,30(3):29-32,47.

[28] Xie XH, Cui YL. Development and test of SWAT for modeling hydrological processes in irrigation districts with paddy rice. Journal of Hydrology, 2011, 396(1/2) : 61-71.

[29］夏智宏,周月华,许红梅. 基于 SWAT 模型的汉江流域水资源对气候变化的响应. 长江流域资源与环境,2010,19 (2) : 158-163.

[30] Mulungu DMM, Munishi SE. River catchment parameterization using SWAT model. Physics and Chemistry of the Earth, $2007,32(15 / 16 / 17 / 18):$ 1032-1039. 